\title{
Discurso de paraninfo, pronunciado pelo Exmo Sr. Professor Lino de Morais Leme, aos bacharelandos de 1955.
}

É com o coração nas mãos que venho acompanhar-vos nesta festa, em que recebereis a investidura que conquistastes pelas provas feitas durante o Curso Acadêmico. Apesar de havermos mourejado juntos nesta Casa quatro anos, e de eu me lembrar, com entusiasmo, das demonstraçôes de vossa inteligência e esforço, e de vossas qualidades morais, e, com reconhecimento, das provas de af eição, que de vós recebi - e que continuaram depois que terminastes o quarto ano, e, portanto, o vosso curso de Direito Civil -, constituiu, para mim, o vosso convite, a maior e a mais agradavel das, suspresas, e a melhor paga, a que eu podia aspirar. Graças a êle ora vos dirijo a palavra, embora sem o brilho com que o faria qualquer um dos meus eminentes colegas e mestres, que tão alto têm sabido colocar o nome de nossa querida Faculdade. Deus vos pague, pelo bem que fizestes à minha alma!

Num exame de consciência, penso ter descoberto o motivo de vossa escolha: quisestes simbolizar, em vosso paraninfo, a preocupação de cumprir o dever e a de fazer justiça, que norteiam os vossos professores e amigos de ontem, colegas e amigos de hoje, de amanhã e de sempre. E assim que se grangeia o respeito e a estima. Foi assim que eu os consegui, nas diversas etapas de minha vida.

Tendo entrado para o magistério secundário apenas com 22 anos de idade, eu costumava distribuir as provas de exame aos alunos - um bom número mais velhos do 
que o professor --, com o objetivo declarado de êles verem os erros cometidos, mas - e êsse naturalmente era silenciado -, para que vissem ter sido o julgamento feito com justiça. (A êsse tempo os professôres não haviam ainda sido vexados com o receberem as provas sem assinatura, lançada em fôlha separada, para identificação posterior). No mesmo ano em que me iniciei no magistério secundário, tive a honra de receber, em minha aula, a visita do grande Rui Barbosa, a quem, tres anos depois, eu iria saudar no Centro de Ciências, Letras e Artes de Campinas, do qual era o orador, quando o insigne brasileiro proferiu, em resposta, o célebre discurso em que descreveu o espetáculo das andorinhas, que então afluiam à tarde, aos milhares, à cidade, voando e fazendo evoluções encantadoras, antes de se acolherem ao prédio que havia sido mercado, e que passou a ser conhecido como a Casa das Andorinhas.

Nesse mesmo ano, um de meus manos, que estava no último ano da Escola em que eu lecionava, teve ocasião de se encontrar com o saudoso, preclaro e virtuoso bispo, Dom Neri, que lhe disse: "Um ano recomendei, a seu mano, vários candidatos aos exames de admissão, mas não fui atendido; no ano seguinte recomendei muito poucos, igualmente sem resultado; finalmente recomendei um único candidato, que também não foi aprovado. Não mais lhe farei pedido. Mas assim é que se procede", e terminou fazendo o elogio da justiça.

Fiz parte, em 1930, da Comissão Central de Sindicância, devido à insistência daquele notável e saudoso varão, que foi Florivaldo Linhares, que não aceitou a minha excusa, por residir eu em Campinas. Pois bem: ao encerrar essa Comissão os seus trabalhos, solidária com o movimento de 1932, tive a honra de ouvir, na despedida, de seu presidente, que era juiz de direito: "Em minha comarca, v. tem o que quiser; até sentenças, sem ler", o que representava, para mim, o maior elogio que eu poderia receber. 
Como vêdes, a preocupação de cumprir o dever e de fazer justiça já me proporcionou tantas satisfações à alma, entre as quais, silenciando outras, a de ser paraninfo, em Campinas, duas vêzes, e, agora, a da homenagem a vossos. professôres, nesta Casa, na pessôa daquele que mais tempo vos acompanhou, dada a extensão do curso de Direito Civil.

Não refiro êsses fatos para me vangloriar, e sim para explicar o sentido de vossa escolha, e para calar mais fundo, se possível, em vossos corações, o amor ao trabalho perseverante, e a preocupação de cumprir o dever e fazer justiça. De Leôncio Correia é êste pensamento: - "Não ha nada mais fácil de praticar do que uma injustiça, e nada mais difícil de esquecer do que uma injustiça", reproduzindo, talvez sem o saber, os conceitos de Platão, em seu Gorgias, de que a injustiça é o maior mal da alma, e de que é melhor sofrê-la do que fazê-la.

Durante os vossos estudos, vistes como o direito organiza a vida social, dando-lhe a estabilidade, que a mantém.

Mas, viver é lutar, disse o poeta, e isso se verifica não apenas nos organismos vivos, vegetais ou animais, mas também na vida espiritual de cada um, e na vida social, tambem ambas em contínuas alterações. Nada ha de definitivo no mundo, disse Duguit (1): tudo passa, tudo se transforma, e.o sistema jurídico, que está em vias de elaborar-se atualmente, deixará logar um dia para outro, que os juristas sociólogos do futuro terão de determinar.

Falar em transformações orgânicas ou sociais, é recordar que elas resultam do princípio da solidariedade, e, poìs, da cooperação. Sem ela não se fará o produto; é ela que lhe dá valor, e não o trabalho individual, como pretendeu Marx.

(1) Las transformaciones del derecho privado, p. 22. 
As transformações, quando lentas ou paulatinas, se dizem resultado da evolução, e, quando rápidas, ou violentas, se dizem operadas pela revolução; mas em ambos os casos se pode verificar a involução, ou seja o aniquilamento, a morte. As sociedades, como as línguas, como os vegetais e os animais - dizem - nascem, crescem, vivem e morrem. Mas devemos guardar-nos de confundir transformações, com morte; assim, por exemplo, não morreu o latim, que continúa a viver nas línguas românicas, em que se transformou. Igualmente não se pode dizer que o direito esteja em declínio (Ripert), (2) que a liberdade esteja em decadência (Halévy), (3) que se verifica um retrocesso à Idade Média (Bardioeff, Gettel), ou a volta ao estado da natureza, pelo desaparecimento da cultura (Chyrippo, Spengler), ou pelas afinidades que manifestam os povos, relativamente a seus pródromos (Rodrigues do Vale) (4). Já Condorcet sustentou que os progressos do homem" pourront suivre une marche plus ou moins rapide, mais jamais elle na sera rétrograde, du moins tant que la terre occupera la même place dans l'univers, et que les lois générales de ce système ne produisent sur le globe ni un bouleversement général, ni des changements qui ne permettraient plus à l'espèce humaine de s'y conserver, d'y déployer las mêmes facultés et d'y trouver les mêmes ressources".

Há os que pretendem denominar de "humanismo" a fase atual do direito, naturalmente adotando um dos sentidos dêsse vocábulo - o de indicar a compaixão e o sentimento de benevolência para com outrem. (Essa palavra recentemente até foi empregada para indicar os processos para a supressão da dor em certos fenômenos da vida). Se assim se pretende indicar a predominância dos interêsses gerais sôbre os particulares, não corresponderia à reali-

(2) Le déclin du droit.

(3) Décadence de la liberté.

(4) Evolução e retorno. 
dade, pois ha muito tempo isso se verifica; se se quer indicar que as classes dominantes passam a ser dominadas por sentimento de benevolência para com as classes inferiores, não corresponderia tambem à realidade. O que ha realmente são transformações do direito, em consequência de imposições da vida social, ou seja das fôrças que lutam na vida social. A sociedade resulta da cooperação, a princípio imposta pelo embrião da família, depois desenvolvida pela necessidade da união dos esforços para a luta da vida. Nessa sociedade primitiva problemas surgiram, exigindo a cooperação - seja para luta contra o poder, seja para melhorar as condições da vida social, ou o equilíbrio social. E fenômenos se verificam, exigindo adaptações que variam, quando resultantes de causas diversas. A cooperação é a lei da vida social, como a adaptação é a da vida física.

Darwin já demonstrou, examinando a sociabilidade entre os animais, a afeição recíproca e a simpatia entre êles, pela referência ao caso do pelicano cego, citado por Stansbury, e do rato cego, que seus congêneres alimentavam. E Ashley Montagu, professor de psicologia da Rutgers University, em New Brunswick, cita o caso de chimpanzés, ajudando-se uns aos outros, de maneira a mais curiosa, chegando os que estão livres a passar alimentos aos que se acham presos; o de elefantes, que se detêm junto a companheiros feridos, para ajudá-los a se levantarem a a fugirem; e a experiência de Lob Seng Tssi, mostrando a cooperação entre gatos e ratos, quando os primeiros não viram as mães atacarem os segundos, o que o levou a enviar cartões aos delegados das Nações Unidas, em Nova York, com estas palavras:" Se ratos e gatos podem cooperar', porque os homens não hão de poder"?

Assim tambem o homem conserva, graças à sua sensibilidade, uma porção de afeição instintiva e de simpatia para com seus semelhantes, resultante de impulsos semi-conscientes, que a razão e a experiência vêm ajudar. Certos impulsos levam o homem a dominar os seus semelhan- 
tes, correspondentes à necessidade fundamental de lutar; e outros impulsos, gerados pela necessidade ou pela simpatia - que são as fôrças de atração, na sociedade levam os homens a se unirem, para alcançarem, pelo esfôrço comum, aquilo que não lograriam conseguir por outra forma. Mas as condições sociais se alteram, e outros aspectos se manifestam, levando as fôrças de atração a se encaminharem noutras direções, e assim sucessivamente.

O fim da ética é encontrar uma solução para essa contradição fundamental, evitando a rudeza da luta, e procurando, tanto quanto possível, realizar o equilíbrio social, que é condição de vida e desenvolvimento da sociedade e do indivíduo. Esse equilíbrio se encontra na cooperação, imposta pelas necessidades gerais, e que se deve fundar no amor, na justiça e na igualdade. Isso pode ser observado em qualquer instituto jurídico.

Em matéria de propriedade, por exemplo, temos as duas posições extremadas - defendendo uns a propriedade coletiva, outros, a individual, sem concessões recíprocas. Ora: os fundamentos da propriedade são a liberdade, o trabalho e a inteligência. A natureza não tem a previdente ternura, imaginada por filósofos do sec. XVIII, e que os poetas da antiguidade decantaram, descrevendo a idade de ouro. E não ha região da qual se possa dizer que seja a Acádia, de que nos fala Longfellow, na Evangeline. A natureza é madrasta, rude, má, adversa. Em planicies férteis se encontram animais bravíos e perigosos, e miasmas de águas pestilentas. $\mathrm{O}$ homem os póde combater graças aos poderes da alma, que o distinguem de outros animais. O sinal de sua personalidade sôbre a matéria é o comêço da propriedade. Assim se diz — a natureza reconheceu o seu senhor.

O homem, para trabalhar, precisa de estímulos; ora, a supressão da propriedade individual viria priva-lo dêsses fundamentos do progresso. $\mathrm{E}$, quanto à propriedade da terra, lembra Stuart Mill ser do interesse da comunidade 
que a terra produza a maior quantidade possível de elementos, de cousas necessárias ou vantajosas para o homem.

A respeito dêsse direito, vistes, em nossas aulas, que ha muito tempo se reconhece ter a propriedade uma função social, tanto que, em Roma, se o proprietário não cultivasse a terra, era permitido que outrem dela se apossasse, para fazê-la produzir. O não se permitir que os mortos fossem enterrados com as suas jóias, dissemos então, era mais uma prova da função social da propriedade. No antigo direito português, como então vos expús, vêm-se tambem algumas providências, mostrando que se tomava em consideração o interesse coletivo; assim, se havia terras apropriadas para sementeiras de trigo, não utilizadas pelo proprietário, permitia-se a outras pessôas fazê-las produzir, como se pode ver nas leis de sesmarias, de 1375. Tambem se alguem tivesse animais próprios para a cultura, e não os utilizasse, era obrigado a cedê-los para aqueles que dos mesmos tivessem necessidade. Nessa ordem de idéias, de se lembrar a propriedade universal, a que se refere Chiaraviglia, (5) diferente, porém, da propriedade coletiva.

Êsses exemplos mostram que não é mister suprimir a propriedade individual, para se atender aos interesses gerais.

Como oberva Zino Zini, (6) fundado em Ruskin - a vontade e a inteligência criaram o mundo moderno dos produtores, como a fôrça um dia criou o dos conquistadores; mas cada dia sente-se mais a necessidade de uma simpática aliança entre êsses lutadores, na batalha da vida. Assim como a gente se indignaria vendo um homem robusto abusar de sua superioridade física, para privar de vantagens justas sêres mais fracos, o mesmo acontece quando alguem se limita a amontoar bens, ou abusa de sua superioridade

(5) Civilizacion del trabajo y de la libertad, p. 136.

(6) Proprietà individuale e proprietà collettiva, p. 249. 
intelectual, sem se preocupar com sêres privados de todo o bem estar, ou em detrimento deles. Não se deve condenar alguem que procura a riqueza legitimamente, como meio de defesa, como garantia da própria existência; mas não é justo que fique privado do mínimo de bem estar aquele que concorreu para a formação dessa riqueza - o que, já em 1378, determinou o movimento dos Ciompi, em Florença.

Houve época em que se fundava o direito em Deus. Depois surgiu a concepção do direito natural, na qual uma corrente vê a sobrevivência da inspiração divina. Veiu mais tarde a escola histórica, sustentando resultar o direito da vida social.

Ligado o direito, a princípio, à religião e à moral, e constituindo êle as regras de conduta necessárias para o equilíbrio social, era natural a luta entre as emanações do egoísmo humano e os princípios morais, manifestações do altruísmo, fôrça gerada pela primeira, como o princípio da ação e reação, na vida universal. Do jôgo de ambas resultou o equilíbrio social. A economia é uma das formas do utilitarismo, e a colaboração, ou a solidariedade, uma das expressões do altruísmo.

Alguns escritores querem fundar a vida social apenas no interesse econômico, que é uma fôrça egoística, e outros na solidariedade, ou cooperação, que é uma fôrça altruística, oposta à primeira. Ora: a vida social é uma resultante de ambas. Eu o procurei mostrar em artigo sôbre a transformação dos contratos.

Tomar em consideração o interesse coletivo, é atitude que o direito sempre adotou, reconhecendo a necessidade de cooperação, sem a qual não haverá vida social; e se atualmente se observam reformas jurídicas feitas ou em andamento, nada mais representam do que a preocupação em se restabelecer o equilíbrio social, que exige, para todos os homens, um mínimo de bem estar, aquele a que têm direito todos os seres humanos, delas privados pelo predomínio das forças egoísticas. 
A cooperação é o resultado - ou da imposição do individuo mais forte, ou do grupo mais forte, no interesse geral e individual, pois o indivíduo é a base da coletividade, e é, pois, a forma que assume o equilíbrio social, em um momento dado. Mas cooperação não quer dizer organização corporativa, que a experiência demonstrou levar à desigualdade e à opressão, entre os membros dessas organizações. (7)

O solidarismo parte da observação de que a saúde física de cada um depende do estado higiênico de todos, da mesma forma que, a moral social, da saúde moral de cada um. Como a vida física depende da solidariedade de todos os órgãos, da mesma forma a saúde moral — ou a alegria e a felicidade - dependem da cooperação de todos. Será, assim, procurando a felicidade dos outros, que se alcança a verdadeira felicidade.

Quando fiz exame de admissão à Escola Normal "Caetano de Campos", o livro adotado, para a prova de francês, era La première année de lecture courante, de Guyau. As histórias que li nesse livro ficaram profundamente gravadas em meu espírito, como lições de uma beleza moral extraordinária. Mais tarde, quando estudei Ética, vim a saber que êsse escritor tinha procurado mostrar, com êsse trabalho, que é possivel estabelecer uma moral independente da religião. Em uma das histórias dêsse livro, sob o título - "Os desejos. Onde está a felicidade?", uma mãe pergunta a seus tres filhos como cada um se julgaria feliz. O primeiro queria ser um general, para dar ordens a tropas e impôr a todos a sua autoridade. O segundo queria ser um rico habitante da cidade, passeando de sobrecasaca e de luvas brancas, e fazendo-se admirar por sua riqueza. $O$ último disse: "Minha mãe: Não sei se serei general ou soldado, rico ou pobre; mas eu que-

(7) Guillermo Cabanellas, Los fundamentos del nuevo derecho, p. 274. 
ria ver todo o mundo feliz ao redor de mim, eu queria ver todo o mundo me sorrir". A mãe o abraçou, e disse-lhe: "Muito bem, meu filho! É vendo todo o mundo feliz, é procurando fazer a felicidade dos outros, que se alcança a verdadeira felicidade! Sê bom, e serás feliz!"

Para melhorar a situação dos que sofrem, a educação moral, na família e na escola, realizará verdadeiros prodígios. Com ela, ter-se-á reforçado e aperfeiçoado o fundamento ético, de modo que o indivíduo não venha a sacrificar o princípio ético-jurídico, que é a fôrça especfica do organismo social. Assim veremos homens que não concordarão com atentados à lei, e que compreenderão que a paz social se encontra no bem estar da coletividade. Graças a Deus ha, em nossa sociedade, elementos nos quais se mantêm vivos êsses princípios, constituindo a esperança de que êles adquirirão, entre nós, a fôrça necessária, integrando o Brasil no grupo daquelas nações em que vigem o culto à lei e o princípio de cooperação. Para isso alcançar, formulemos votos para que o nosso ensino não se limite à educação física e à intelectual, mas que a educação moral venha completá-lo, ajudado por uma literatura didática, que faça frutificar o exemplo de Guyau.

Meus carissimos paraninfados!

Ides inciar a vida prática na véspera de início de um novo Govêrno, eleito pela Nação, e a vosso espírito naturalmente acudirão, em face dos acontecimentos posteriores às eleições, pensamentos como o de Lieber: "As leis e as instituições não são mais do que fórmulas mortas, se não funcionam"; e o ensinamento do direito romano - Legum servi sumus ut liberi esse possumus - Sejamos servidores da lei, para que possamos ser livres.

$O$ novo Govêrno tem tarefas ingentes a realizar: combater a amoralidade, com a qual se acumplicíam aqueles que, tendo poder e daí o dever, não mandam apurar abu- 
sos por parte dos que se aproveitam das posições, para delas tirarem o maior provento ilícito possível; combater a inflação, que se desenvolve assustadoramente, concorrendo para a exacerbação das dificuldades econômicas e sociais; pôr fim a leis de exceção e inconstitucionais, praga contra a qual já clamava Calderón, em sua pátria, em 1920 (8); resolver problemas sociais, que nem ao menos tem sido estudados, e de que são um exemplo as "favelas", especialmente na Capital Federal, onde se apresentam com um carater grave, pois sua população tem aumentado constantemente, sendo atualmente de mais de 500.000 pessoas, sem que se conheçam estatísticas sôbre as condições sociais delas e sôbre a situação higiênica de suas habitações; pôr em ordem a nossa vida econômica e financeira; e trabalhar por um Brasil maior e melhor, que se possa apresentar de fronte erguida perante as demais Nações. Que Deus oriente êsse Govêrno, para o bem da Pátria amada! E que êsse Govêrno venha a receber, afinal, a bênção do Brasil!

O destino vos levará para a advocacia, a magistratura, a política, ou seja para posições de grande importância social. E muitos de vós, acredito, virão sentar-se a nósso lado, ou em nossos logares.

Do advogado, diz o Digesto: que em Roma não se permitirá o exercício da advocacia, senão às pessoas dignas (C. II-VI, 1.6, § 3); e que "os advogados que esclarecem as questões duvidosas, e que, por seus esforços e talento, tanto nos assuntos públicos como nos particulares, salvam umas vêzes de ruína iminente, e devolvem outras, uma fortuna perdida, não são menos uteis ao gênero humano do que os que defendem a pátria e a lei, com armas na mão. Não creio, por isso, que militem apenas os que estão armados de espada, escudo e couraça, mas tambem os advogados militam na verdade, defendendo, com sua eloquência e ta-

(8) La libertad y el derecho. 
lento, os direitos dos que sofrem, alimentam suas esperanças e salvam as vidas de seus clientes e de seus filhos" (C., II-VII, 1. 14).

O juiz, o advogado, o político, o mestre, não estão em planos diferentes. O advogado defende o direito; o juiz o aplica; o político o adapta às novas condições sociais; o mestre o ensina. São funções que se completam. Sòmente espíritos tacanhos podem imaginar que o advogado e o juiz estejam em polos opostos. Os advogados procuram esclarecer as questões, debatendo-as; o juiz vem como um elemento desempatador, por assim dizer, dando razão à parte que a tem, depois de pesar, na balança da justiça, as razões apresentadas pelas partes. Como um juiz mau não desmoraliza a magistratura, tambem um mau advogado não deve deslustrar a advocacia. Os órgãos do Ministério Público exercem tarefas de assistência e proteção, semelhantes às dos advogados.

Essas funções são, em suma, a defesa do direito e da lei, a prática da justiça. Os advogados e os magistrados são sacerdotes do Direito e da Justiça. Da importância de sua missão, bem alto dizem as vestes talares com que se apresentam.

Entre os nossos praxistas, figura Guerreiro, que escreveu nove alentados volumes, em latim, como o faziam os praxistas, e todos com observações ou notas, em tão grande quantidade, que levam o espírito a avaliar o tempo empregado na elaboração dêsses trabalhos; e corôou a sua vida escrevendo um volume em português, em 1759, intitulado Escola moral, política, cristã e jurídica. Neste, depois de dois capítulos intitulados "Ao leitor benévolo" e "Ao leitor malévolo" (êste bem mais extenso do que aquele), e do proêmio, entra nas "lições", que se desdobram em quatro "palestras". Essa obra está cheia de ensinamentos, que devemos recordar cada dia, entre os quais êstes: "Todo - bem da República consiste em que inviolavelmente se observem as leis, que a governam"; recordando palavras 
de Justiniano - "que o Imperador, de quem depende a saúde da República, não só deve estar cercado de armas, mas tambem acompanhado de leis"; lembrando conceitos: de Cícero - "Assim como o corpo não pode viver sem alma. assim a Cidade não pode sustentar-se sem leis"; e que "muitas cidades se defendem sem muralhas, porém sem leis nenhuma se conserva"; que a justiça é "rainha de todas. as virtudes", e "povo sem justiça é corpo sem alma". Não quero deixar de lembrar as palavras dele sôbre o conceito de justiça, a qual, "conforme o jurista, é: Uma constante" e perpétua vontade de dar a cada um o seu direito; convém. a saber: a Deus, obediência; a si mesmo, santidade; ac. maior, reverência; ao igual, concórdia; ao menor, doutrina: ao inimigo, paciência; ao pobre, misericórdia; e por isso é a Justiça Paz dos povos, guarda, e amparo da Pátria; privilégio, e isenção dos súditos, temperança dos ares, serenidade do mar, fortuna da terra, alegria dos pobres, cuidado e regalo dos enfermos, herança dos filhos, e ao mesmo Rei fiadora abonada da Bemaventurança, que espera, como escreve São Gregor. no livro 5 dos Anais".

São conceitos que recordam os de Platão — "Da mesma forma que ha uma ordem, uma harmonia, que dá saúde e fôrça ao corpo, ha uma ordem, um equilíbrio da alma. que se obtém pela justiça.

Cícero, no De amicitia, lembra que todas as cousas do mundo estão sujeitas às leis da simpatia e da antipatia. $\mathrm{E}$ nós podemos acrescentar que uma das formas de converter a fôrça de repulsão em fôrça de atração, as auras que se repelem em auras que se atraem, é ter a constante preocupação da justiça, da qual é uma das formas a solidariedade ou a cooperação.

Deve tambem o homem fortalecer a sua alma, mostrando que êle é um bom lutador, não se deixando abater pelos revezes, que sofrer: antes êles devem levá-lo a red̉obrar de esforcos, lembrando-se sempre de que "querer é. poder". Para vencer na vida, é preciso que o homem 
"queira", aplicando, na realização de seu objetivo, todos os esforços. Paul Doumer publicou um livro magnífico "Vouloir c'est pouvoir", com um repositório dos mais lindos ensinamentos, mostrando que só os fracos. os covardes, os pusilânimes, é que se deixam abater.

Flammarion fala, em uma de suas obras, da pedra lunar, a cujo toque os individuos sentem-se transportados para uma região ideal, onde reina uma primavera eterna, em que se não observam as lutas da natureza, para restabelecer o equilíbrio rompido, em que se não vê o tumultuar das paixões, por isso que nessa região sòmente ha corações que se procuram, espíritos que se atraem, almas que se unem. Ali não existe a lei da repulsão, porque assim como não ha flor sem perfumes, ali se não encontra coração sem bondade, espírito sem a idéia da solidariedade.

Se êsse ideal é inatingivel, todavia, servindo ao ideal de justiça. e, portanto, ao da solidariedade, ter-se-á melhorado consideravelmente a vida social e a vida individual.

Meus carissimos afilhados!

Estou certo de que, no coração e no espírito de todos vós, estão as idéias que acabo de expôr.

Durante o vosso Curso, demonstrastes a preocupação de assimilar as noções que nós, professores, vos transmitíamos, e assim constituís uma pleiade brilhante, da qual nos orgulhamos. E, em vosso trato quotidiano, procurastes cercar de simpatia a todos nós. Por tudo isso, bem podeis avaliar o entusiasmo e a cordialidade que nos empolgam neste momento, e a certeza, que temos, de que triunfareis na vida, tendo como alicerce o trabalho perseverante, como inspiração, a justiça, e como finalidade servir ao ideal, que, diz Rénan, consiste em fazer o bem, descobrir a verdade e realizar o belo. 
Com a vossa partida, não vos separareis de nossa querida Faculdade, que conta convosco para manter as suas gloriosas tradições, e que acompanhará carinhosamente os vossos passos.

Como a luz do sacrário, que precisa ser renovada constantemente, assim tambem os fachos de luz, que tornaram gloriosa esta Casa, precisam ser renovados constantemente, para que essa glória se mantenha. E ela conta convosco para se manter esplendorosa a luz que outros filhos seus acenderam, e que as gerações acadêmicas vêm mantendo carinhosamente.

Pelas campanhas, em que a mocidade das Arcadas 'se tem empenhado, em prol da Pátria, do Direito e da Justiça, tem-se a impressão de que a Faculdade é um altar, com os seus ministros e os seus devotos, com a água benta, que abençôa, e o turíbulo, para incensar êsses símbolos, quais numes tutelares de um culto sempre vivo em nossa coração e em nosso espírito.

À sombra dêsses numes, imbuídos de um grande amor, de uma fé ardente e de uma vontade férrea, vencereis, e deixareis um rastro luminoso de vossa passagem pela vida.

São os votos ardentes de vossos professores, hoje colegas e amigos, que se unem a vossas famílias e a vossos outros amigos, acompanhando, com um "Excelsior", o brado que parte de vossos corações e de vossos espíritos - pela Rátira, pelo Direito e pela Justiça! 